\title{
Impacted Foreign Body in Meckel's Diverticulum-A Rare Complication in Children
}

\author{
Akshay Kalavant* \\ Consultant Pediatric Surgeon and Urologist, SDM College of Medical Sciences, India
}

Submission: September 17,2019; Published: September 27, 2019

*Corresponding author: Akshay Kalavant, Consultant Pediatric Surgeon and Urologist, SDM College of Medical Sciences, Dharwad, India

\section{Introduction}

Meckel's Diverticulum (MD) is the most common congenital anomaly in GIT. It was named after Johann Freidrich Meckel, who established its embryological origin in 1809 , said to be caused by failure of omphalomesenteric duct to recede during gestational weeks of 5-7 [1]. Though MD are asymptomatic, children present with complications like bleeding, perforation and intussusception, while adults often present with intestinal obstruction [2]. However, foreign bodies like fish bone, chicken bone, needles, and button batteries have been reported to be found in MD but often seen to be associated with perforation [3-5]. Asymptomatic foreign body in $\mathrm{MD}$, in youngest child, for 45 days long, without perforation is one of its own kind and has been described below.

\section{Case}

A 1year 5-month-old girl baby, presented with ingestion of closed safety pin 45 days ago. Mother gave history of consulting local practitioner who had monitored the child clinically and radiologically with repeat X-rays in examination her vitals were in the normal range. Abdomen was soft and non-tender. Bowel sounds heard. Her complete hemogram was normal. X ray abdomen showed closed safety pin in the right iliac fossa (RIF), vertical in alignment which was in the same state in all the previous X-rays, with no pneumoperitoneum (Figure 1). Bowel irrigation was tried to expel the foreign body but was not fruitful. The case was taken up for diagnostic laparoscopy. $10 \mathrm{~mm}$ port in umbilicus showed adhesions between the region of distal ileum and anterior abdominal wall. Through $5 \mathrm{~mm}$ port adhesions were released, which showed MD with impacted safety pin within its lumen. MD was inflamed but without the perforation and base was healthy. Through the umbilical port, MD was delivered out (Figure 2). Wedge resection and closure was done with Hand sewn technique and surgical ports were closed (Figure 3). Histopathology reported a MD with intestinal mucosa. Patient had uneventful post-operative period. Was started on feeds on day 4 and was discharged on day 6. Child was playful during the next follow ups.

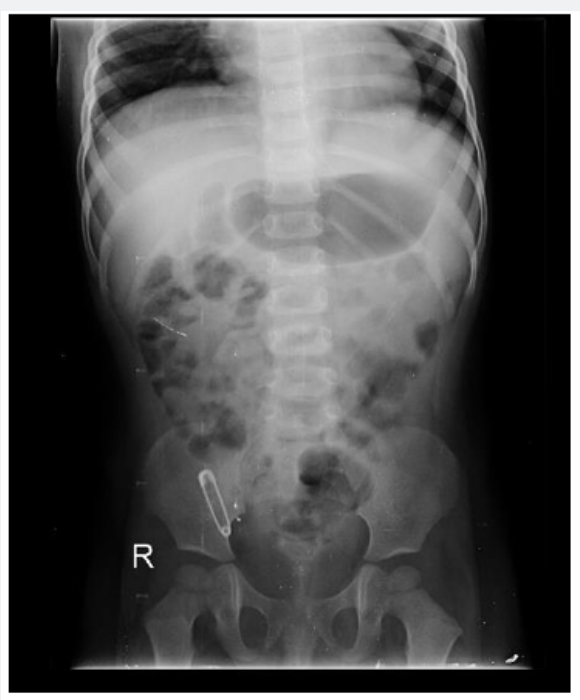

Figure 1: Safety pin impacted in vertical position in radiograph. 


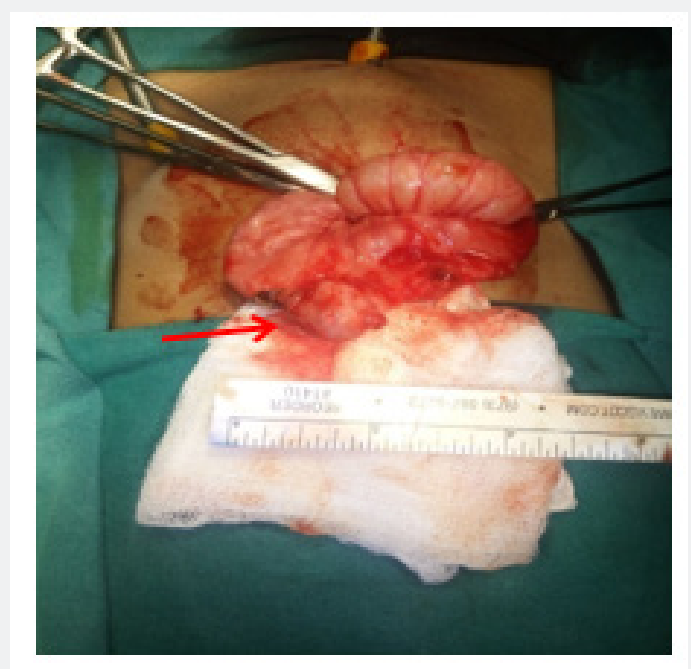

Figure 2: Meckel's diverticulum with impacted foreign body in it.

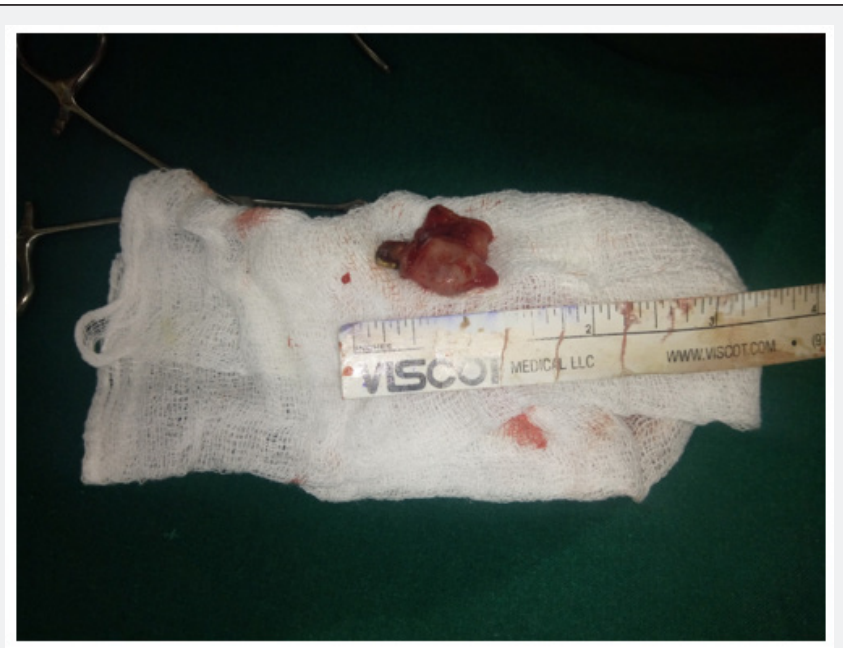

Figure 3: Excised specimen.

\section{Discussion}

MD, being the most common congenital anomaly of GIT, is situated in the antimesenteric border, containing all the 5 layers of intestine, with its own blood supply from superior mesenteric artery. Hence, designated as a 'true diverticulum'. The majority of foreign body ingestions occur in the pediatric population, with a peak incidence between the ages of 6 months and 6 years. In adults, true foreign body ingestion (i.e., nonfood objects) occurs more commonly in those with psychiatric disorders, developmental delay, alcohol intoxication [6]. Lodgment of foreign body in MD and presenting with complication has been documented in the literature in as young as 1 year of age [5]. Incidence of complications due to MD range from 4-16\% [7]. Most common being hemorrhage (38\%-bleeding from the ulcers in case of ectopic mucosa), obstruction (34\%), diverticulitis (22\%). The rare complications in children include tumors like Burkitt's lymphoma, adenocarcinoma and sarcoma and perforation by foreign bodies [8]. The most common foreign bodies causing perforation in MD is ingested bone fragments (58\%), followed by wood splinters (14\%), food (2\%), pin/needles (9\%) and is cellaneous (7\%) [9]. Sharp pin and nail ingestions constitute for $13 \%$ of foreign body ingested according to Asian studies [10]. The proposed mechanism for FB entering the MD include disordered motility at the diverticulum and wide based opening of diverticulum, [9] acting as sump to debris and foreign bodies in the bowel lumen (sump syndrome) [11]. The combined effect of local bacterial inflammation along with stasis and pressure necrosis of the diverticular wall can be the mechanism of perforation [12]. It is proved that there is $8 \%$ chance of perforation of MD by foreign body [13].

Ingestion of button batteries adds to the significant morbidity in pediatric population, due to their physical and chemical nature. Most of the children with button battery lodged in MD have presented with complications within 6 days of ingestion $[5,14]$. Multiple magnetic foreign body ingestion has been proved to splint adjacent sections of bowel causing pressure necrosis and fistulation [15]. Even vegetative foreign bodies like rolled tomato 
skins, cabbage stalks and melon seeds have been reported in literature to cause perforation $[3,16]$. Average transit time for spontaneous expulsion of foreign object from GIT in children and the sharp object leading to hollow viscus perforation has been reported to be 3.6 days and 10.4 days respectively. If the foreign body has been static on imaging for 3 days or the patient becomes symptomatic, surgical removal may be considered [10]. However, no literature gives information regarding how long can a foreign body be left in GIT for its spontaneous expulsion. In our case, foreign body stayed for the duration of 45 days without complications, though it could have caused, if left surgically untreated. The course, complications and the outcome, vary with the type of foreign body and the patient, and is unpredictable. The inert nature of the foreign body can be attributed to the uncomplicated state in our case. In a case reported, 2.5-yearold child swallowing a button battery, the perforation site was adherent to the cecum and appendix [5]. Similar adhesions were seen in our case as well. Thus, it is always better to carefully examine the adjacent bowel on the table to rule out additional pathology. Radio opaque foreign bodies do not need further investigation other than an x-ray, but radiolucent foreign bodies like wood or fish bones might need computed tomography scan, ultrasounds, magnetic resonance imaging, and upper GI contrast study [10]. Most of the reported cases of foreign body in MD were associated with complications, mainly perforation. On observation of serial abdominal radiographs, it can be commented that a vertically standing foreign body in right iliac fossa for long period, can be assumed to be lodged in MD. Our case can be considered as second youngest child to have lodged foreign body in the MD [5]. Endoscopic intervention is recommended in case of foreign body in esophagus if it has not progressed down within 24hours, because delay in the intervention increases the risk of complications including risk of perforation $[17,18]$. Although the majority of sharp-pointed objects in the stomach will pass without incident, the risk of a complications caused by a sharp pointed object is as high as 35\% [6]. Therefore, a sharp pointed object in the stomach or proximal duodenum should be treated endoscopically if that can be accomplished. Once it enters the gut, periodic monitoring is done to document their passage, until foreign body is expelled in stools, and surgical intervention should be considered for objects that fail to progress after 3 days as recommended by NAGPAH Committee [6]. Indications for emergency laparotomy are signs of complication such as inflammation, perforation and arrested mobility of foreign body in serial X-rays in asymptomatic patients. The surgical options for retained foreign body in the MD are simple diverticulectomy or segmental bowel resection and anastomosis. Bowel resection is indicated in cases where the diverticulum has a wide mouth with ectopic tissues, when an inflammatory or ischemic process involved the adjacent ileum, or when the base of the diverticulum is edematous, inflamed or perforated $[7,19]$. Laparoscopic approach is preferred as it reduces the invasiveness and aids in early recovery.

\section{Conclusion}

The case highlights the fact that any foreign body in the static position in RIF in serial radiologic studies could be considered to be in MD. The case of foreign body in MD in the young girl, for longest duration, with absolutely no symptoms and complications and timely surgical intervention with uneventful post-operative period makes it an interesting case.

\section{References}

1. Pollak Raymond (2007) Adjunctive Procedure in Intestinal Surgery. Mastery of surgery pp 1392-1393.

2. Schmidt C, Brown LM, Klomp HJ, Henne Bruns D (2001) Perforated Meckel's diverticulum. Surgery 129(5): 643-644.

3. Rosswick RP (1965) Perforation of Meckel's diverticulum by foreign bodies. Postgrad Med J 41: 105-107.

4. Yagci G, Cetiner S, Tufan T (2004) Perforation of Meckel's diverticulum by a chicken bone, a rare complication: report of a case. Surg Today 34(7): 606-608.

5. Karaman A, Karaman I, Erdogan D, Cavusoglu YH, Aslan MK, et al. (2007) Perforation of Meckel's diverticulum by a button battery: report of a case. Surg Today 37(12): 1115-1116.

6. Ikenberry So, Jue TL, Anderson MA, Appalaneni V, Banerjee S, et al. (2011) Management of ingested foreign bodies and food impactions. Gastrointest Endosc 73(6): 1085-1091.

7. Sagar J, Kumar V, Shah DK (2006) Meckel's diverticulum: a systematic review. J R Soc Med 99(10): 501-515.

8. Park JJ, Wolff BG, Tollefson MK, Walsh EE, Larson DR (2005) Meckel diverticulum: the Mayo Clinic experience with 1476 patients (19502002). Ann Surg 241(3): 529-533.

9. Redmond P, Sawaya D, Nowicki M (2014) Bowel obstruction due to multiple retained foreign bodies in a Meckel diverticulum. J Pediatr 165(3): 639.

10. Kramer RE, Lerner DG, Lin T, Manfredi M, Shah M, et al. (2015) Management of ingested foreign bodies in children: a clinical report of the NASPGHAN Endoscopy Committee. J Pediatr Gastroenterol Nutr 60(4): 562-574.

11. Michael A, Benedict D, Razali I, Jasjit SN, Zainal AA (2016) A curious case of Meckel's diverticulum. Med J Malaysia 71(4): 203-205.

12. Sharma RK, Jain VK (2008) Emergency surgery for Meckel's diverticulum. World J Emerg Surg 3: 27.

13. Groebli Y, Bertin D, Morel P (2001) Meckel's diverticulum in adults: retrospective analysis of 119 cases and historical review. Eur J Surg. 167(7): 518-524.

14. Willis GA, Ho WC (1982) Perforation of Meckel's diverticulum by an alkaline hearing aid battery. Can Med Assoc J 126(5): 497-498.

15. Lindley S, Pathak S, Mulchandani M, Dalton S, Sutton R (2012) Magnetic Meckel's: an unusual case report of foreign body ingestion. J Surg Case Rep 3:7.

16. Okur MH, Arslan MS, Aydogdu B, Uygun I, Otcu S, et al. (2014) Perforation of Meckel's diverticulum by foreign body. J Pak Med Assoc 64(7): 826-827.

17. Loh KS, Tan LK, Smith JD, Yeoh KH, Dong F (2000) Complications of foreign bodies in the esophagus. Otolaryngol Head Neck Surg 123(5): 613-616. 
18. Park JH, Park CH, Lee SJ, Lee WS, Joo YE, et al. (2004) Review of 209 cases of foreign bodies in the upper gastrointestinal tract and clinical factors for successful endoscopic removal. Korean J Gastroenterol 43(4): 226-233.
This work is licensed under Creative Commons Attribution 4.0 Licens

DOI: 10.19080/AJPN.2019.07.555785

\section{Your next submission with Juniper Publishers will reach you the below assets}

- Quality Editorial service

- Swift Peer Review

- Reprints availability

- E-prints Service

- Manuscript Podcast for convenient understanding

- Global attainment for your research

- Manuscript accessibility in different formats

( Pdf, E-pub, Full Text, Audio)

- Unceasing customer service

Track the below URL for one-step submission https://juniperpublishers.com/online-submission.php 